\title{
Sensitivity to Azoxystrobin Among Isolates of Uncinula necator: Baseline Distribution and Relationship to Myclobutanil Sensitivity
}

\author{
Francis P. Wong and Wayne F. Wilcox, Department of Plant Pathology, Cornell University, New York Agricultural \\ Experiment Station, Geneva 14456
}

\begin{abstract}
Wong, F. P., and Wilcox, W. F. 2002. Sensitivity to azoxystrobin among isolates of Uncinula necator: Baseline distribution and relationship to myclobutanil sensitivity. Plant Dis. 86:394404.

Two hundred fifty-six single-conidial chain isolates of Uncinula necator were assayed for their sensitivity to azoxystrobin and myclobutanil. These isolates were collected from two sites in New York in 1999: an "organic" vineyard where no synthetic fungicides have been used (baseline population) and a commercial vineyard having a history of compromised powdery mildew control with myclobutanil (demethylation inhibitor [DMI]-resistant population). Mean coefficients of variance for a leaf disk assay used to test fungicide sensitivities were $31 \%$ for azoxystrobin and $41 \%$ for myclobutanil. Baseline $\mathrm{ED}_{50}$ values ranged from 0.0037 to $0.028 \mu \mathrm{g} / \mathrm{ml}$ (mean $0.0097 \mu \mathrm{g} / \mathrm{ml}$ ) for azoxystrobin and from 0.0049 to $0.69 \mu \mathrm{g} / \mathrm{ml}$ (mean $0.075 \mu \mathrm{g} / \mathrm{ml}$ ) for myclobutanil. A shift in the mean $\mathrm{ED}_{50}$ value for azoxystrobin to $0.018 \mu \mathrm{g} / \mathrm{ml}$ was observed in the DMI-resistant population; with the strongest shift observed for isolates collected from vines treated exclusively with myclobutanil $(0.024 \mu \mathrm{g} / \mathrm{ml})$. For the 256 tested isolates, there was a moderate, but statistically significant, correlation between azoxystrobin and myclobutanil sensitivities $\left(R^{2}=0.36, P<0.001\right)$. Tests with three other strobilurin fungicides (kresoxim-methyl, pyraclostrobin, and trifloxystrobin) indicate clear differences in the intrinsic activity of these compounds against $U$. necator, and the applicability of the methods developed with azoxystrobin for assays with pyraclostrobin and trifloxystrobin. Isolates from the high and low ends of the azoxystrobin sensitivity distribution (15× difference in mean $\mathrm{ED}_{50}$ values) were equally controlled in planta by protectant or postinfection treatment with azoxystrobin at $250 \mu \mathrm{g}$ a.i. $/ \mathrm{ml}$, but postinfection application at lower rates $(2.5$ and $25 \mu \mathrm{g}$ a.i./ml) resulted in a 41 and $44 \%$ decrease, respectively, in the control of the low-sensitivity isolates versus high-sensitivity isolates. The results of this study document the baseline sensitivity distribution of $U$. necator to azoxystrobin, provide evidence of partial cross-sensitivity between azoxystrobin and myclobutanil, and illustrate the potential selection for individuals with reduced sensitivity (quantitative range) to azoxystrobin by postinfection application and reduced rates of this fungicide.
\end{abstract}

Grapevine powdery mildew, caused by the obligate biotrophic ascomycete $U n$ cinula necator (Schwein.) Burrill, is a major fungal disease of grapevine worldwide (31). Without the implementation of control measures, primarily the regular application of fungicides, this disease can cause severe losses in yield and fruit quality. The strobilurin fungicides are part of the $Q_{0} I$ class of fungicides, which inhibit mitochondrial respiration by blocking electron flow through the electron transport chain by binding to the $\mathrm{Q}_{0}$ site of the cytochrome $b_{1}$ complex (17). Several strobilurin fungicides have been registered recently or are currently under development for the control of $U$. necator. These materials are unique in the sense that they are the first site-specific crop protection compounds that are effective against $A s$ -

Corresponding author: F. P. Wong

E-mail: frank.wong@ucr.edu

Accepted for publication 28 November 2001.

Publication no. D-2002-0212-03R

( 2002 The American Phytopathological Society comycetes, Basidiomycetes, and Oomycetes (1-3,15,18,27,28,39).

A number of species of plant-pathogenic fungi and oomycetes developed practical resistance to the strobilurin fungicides soon (one to three seasons) after their use became widespread, including Blumeria graminis, Mycosphaerella fijiensis, Plasmopara viticola, Pseudoperonospora cubensis, Sphaerotheca fuliginea, and Venturia inaequalis $(11,12,17)$. At least two potential mechanisms of resistance to strobilurins have been demonstrated for fungi in vitro, target site mutations in cytochrome $\mathrm{bc}_{1}(5,8,25,41)$ and the induction of alternative respiration $(41,42)$. However, the exact mechanism has not been confirmed for all of the aforementioned cases of practical resistance.

One of the first commercial strobilurin fungicides, azoxystrobin, was labeled for use on grapevine in the United States in 1997 and has been shown to be highly effective for the control of $U$. necator and other fungal pathogens of this crop, including the oomycete $P$. viticola $(37,38)$. In order to minimize the risk of resistance development, product labels for azoxystrobin and other strobilurin fungicides specify that these materials be used a limited number of times during a growing season, mandating their rotation with fungicides that have different modes of action. For $U$. necator, the sterol demethylation inhibitors (DMIs) represent one such rotational partner. The DMIs have been a cornerstone of grapevine powdery mildew management since the early 1980s, and although shifts toward insensitivity and practical resistance have occurred in some vineyards $(10,16,40)$, they still provide adequate control of the disease in many others. In New York, azoxystrobin and DMI fungicides are often used together in rotational programs to manage both grapevine powdery mildew and the development of resistance to each group of compounds.

Recent developments in fungicide resistance research have suggested the need for a closer examination of the relationship between DMI and strobilurin sensitivities. First, studies with $V$. inaequalis in New York (W. Köller and W. F. Wilcox, unpublished) have indicated that strobilurin and DMI sensitivities are not completely independent traits for this pathogen. Second, related work on the interaction of fenarimol and dodine also indicated that there is an unexpectedly positive relationship between sensitivities to these two unrelated fungicides in $V$. inaequalis $(21,24)$. There is also recent evidence in $V$. inaequalis that there is a potential predisposition of fungicide resistance to develop more rapidly to multiple classes of chemistries (22). Third, recent investigations of multidrug resistance in fungi have indicated that crossresistance can develop to unrelated compounds $(6,7)$. Finally, there have been anecdotal observations that strobilurin resistance developed first in pathogens that had been heavily exposed to DMI fungicides. If there is a sufficient lack of independence for DMI and strobilurin sensitivities, then resistance-management practices could be compromised, and current fungicide-use strategies would have to be reconsidered.

Therefore, the broad objective of this study was to examine the relationship between sensitivities to strobilurin and DMI fungicides within $U$. necator populations, using azoxystrobin and myclobutanil, respectively, as representative compounds, and to relate these findings to practical resistance-management programs. Specific sub-objectives were to (i) develop a method for assaying the sensitivity of $U$. necator isolates to azoxystrobin, (ii) use the method to determine the baseline sensi- 
tivity distribution for this pathogenfungicide combination, and (iii) explore the utility of this method with respect to examining the sensitivity of $U$. necator to other strobilurin fungicides.

\section{MATERIALS AND METHODS}

Fungicides. Technical grade azoxystrobin (98\% active, Syngenta Crop Protection, Greensboro, NC), kresoximmethyl (93\% active, BASF Corporation, Research Triangle Park, NC), myclobutanil (93\% active, Dow AgroSciences, Indianapolis, IN), pyraclostrobin (93\% active, BASF Corporation) and trifloxystrobin (96\% active, Bayer Corporation, Kansas City, KS) were used for this study unless otherwise noted. The fungicides were dissolved in acetone to provide stock solutions containing $10 \mathrm{mg} / \mathrm{ml}$ of each fungicide. All stock solutions were stored at $-20^{\circ} \mathrm{C}$ in $2-\mathrm{ml}$ cryovials (Fisher, Pittsburgh, PA) sealed with Parafilm.

For field and greenhouse studies, the fungicides were applied as formulated product: Nova 40W (40\% active, Dow AgroSciences) and Abound 2.08F (23\% active, Syngenta Crop Protection).

$\boldsymbol{U}$. necator populations. Two sites were chosen for this study, and U. necator populations from both had been characterized in 1995 for myclobutanil sensitivity (10). The first site was an "organic" vineyard in an isolated location in Burdett, NY, where neither DMI nor strobilurin fungicides have been used. U. necator isolates from this site were considered representative for baseline populations with respect to both fungicides, and for the purpose of this study, this vineyard was considered the "baseline site." The second site was a commercial vineyard with a long history of DMI use and high frequency of DMIresistant $U$. necator isolates (10). For the purpose of this study, this was referred to as a "DMI-resistant site." Since 1996, a number of experimental fungicide spray programs had been imposed there to assess their effects on further shifts toward fungicide insensitivity within the $U$. necator population (35). For this study, samples were collected from three such experimentally imposed treatments: (i) no fungicides throughout the growing season, (ii) six applications of myclobutanil (112 g a.i./ha); and (iii) four applications of azoxystrobin (200 $\mathrm{g}$ a.i./ha) alternated with two of myclobutanil (112 g a.i./ha) (Table 1). Fungicide applications were initiated at approximately 2 weeks prebloom and continued at 2-week intervals until veraison. Commercial fungicide formulations were applied with a hooded-boom sprayer at 207 $\mathrm{kPa}$ in a volume of 467 liters/ha for the two prebloom sprays and 936 liters/ha thereafter. Each treatment was replicated three times in randomized complete blocks, with each individual plot consisting of five rows of 15 vines. Disease was assessed 1 to 2 weeks before harvest (Sep- tember) based upon disease severity as measured by the percentage area infected of 25 grape clusters from the center of each replicated plot. Severity ratings were made using the Barrett-Horsfall scale before conversion to percentage cluster area infected.

Collection and maintenance of isolates. In late-August of 1999, approximately 150 infected leaves were sampled arbitrarily from a block of approximately 1,000 Vitis $\times$ labruscana $\mathrm{cv}$. Concord vines at the baseline site. Sixty-eight singlechain isolates were obtained from this site, as described below.

In September of 1999, approximately 50 infected leaves were sampled from each replicate plot of the three experimentally imposed fungicide treatments located at the DMI-resistant site, 2 weeks after the last fungicide application. To minimize interplot interference, samples were taken from the young, terminal leaves of the nine center vines within the three middle rows of each plot, then approximately 60 singlechain isolates were obtained for each of the treatments (Table 1) and maintained subsequently, as described below.

During the sampling procedure, young, infected terminal leaves were placed individually into small plastic bags, transported to the lab, and incubated for 1 day in humid chambers to promote additional sporulation. Sporulating colonies were excised from the leaves and placed into 60$\mathrm{mm}$ petri dishes containing approximately $15 \mathrm{ml}$ of $1.5 \%$ water agar (Difco, Detroit, MI). Approximately 3 days later, singleconidial chain isolates were obtained by transferring a single chain of conidia to 12mm-diameter, surface-disinfested Vitis vinifera $\mathrm{cv}$. Chardonnay leaf disks with the adaxial surface exposed, using a single camel hair attached to a $15-\mathrm{mm}$ disposable glass Pasteur pipette with paraffin wax. Transfer tools were disinfested by placing them in $70 \%$ ethanol for $10 \mathrm{~min}$, then $95 \%$ ethanol for $30 \mathrm{~s}$, and were thoroughly airdried before use. Transfers were made with the aid of a dissecting microscope. Leaf disks (12 $\mathrm{mm}$ diameter) were prepared as described previously $(10,37)$, with the exception of surface disinfesting leaves for $30 \mathrm{~s}$ in a solution of calcium hypochlorite (0.86 g/liter) instead of ethanol (10), or sodium hypochlorite and Tween 20 (37). Vines were grown in a greenhouse that was maintained at $37^{\circ} \mathrm{C}$ to reduce contamination by $U$. necator $(9,40)$. Only the highly susceptible, expanding, translucent leaves from leaf positions 2 and 3 distal to the shoot tip were used, as U. necator infection and growth on these are more uniform than on older leaves $(9,10)$. Inoculated leaf disks were incubated at ambient room temperature $\left(20\right.$ to $\left.24^{\circ} \mathrm{C}\right)$ with alternating 12-h periods of darkness and fluorescent light.

Approximately 7 to 10 days later, a single-conidial chain from a newly sporulating colony was transferred to a new set of leaf disks (prepared as described above) to obtain a single-chain isolate. For each isolate, the procedure was conducted three times in succession over three generations of the fungus to ensure the purity of the single-chain isolates. A total of 256 singlechain isolates was obtained in this way (Table 1), and the isolates were maintained by biweekly transfers of several chains of conidia to freshly prepared leaf disks, which were maintained as described previously.

Fungicide sensitivity assays. Assays were based upon the technique described in detail by Erickson and Wilcox (10). Briefly, Chardonnay leaf disks were prepared as described above, taking care to excise them from areas of the leaves without major veins ( $\geq 1 \mathrm{~mm}$ wide), to minimize any radial distortion of the expanding $U$. necator colonies. Excised disks were randomized and placed into glass beakers containing azoxystrobin or myclobutanil solutions ranging from 0.00049 to 8.0 $\mu \mathrm{g} / \mathrm{ml}$ at fourfold dilutions, in type $\mathrm{I}_{2} \mathrm{O}$ (HPLC-grade nanofiltered sterile water), or type $\mathrm{I}_{2} \mathrm{O}$ only (check treatment). Solutions were derived from technical grade fungicides dissolved in acetone, and acetone concentrations $\left(1 \times 10^{-5}\right.$ to $\left.0.8 \mathrm{mg} / \mathrm{ml}\right)$ were not normalized, as acetone concentrations of $\leq 5 \mathrm{mg} / \mathrm{ml}$ were shown previously (10) not to affect the growth of U. necator under these conditions.

Leaf disks were submerged in the solutions for $1 \mathrm{~h}$, with regular agitation, then they were blotted dry between clean paper towels. Four disks per fungicide treatment were placed, with the adaxial surface exposed, into $60-\mathrm{mm}$ petri dishes containing approximately $15 \mathrm{ml}$ of $1.5 \%$ water agar. After incubation overnight at ambient room temperature, each disk in a petri dish was inoculated at a single point with two to three conidial chains (approximately 15 to 30 conidia) from an individual $U$. necator isolate. Inoculated leaf disks were incu-

Table 1. Origin and size of samples of Uncinula necator isolates

\begin{tabular}{llllc}
\hline Population & Group & Treatment & Timing $^{\text {z }}$ & No. of isolates \\
\hline Baseline & Bl & None & $\ldots$ & 68 \\
DMI-resistant & Em & Myclobutanil (112 g a.i./ha) & $1-6$ & 69 \\
& Ea & Myclobutanil (112 g a.i./ha) & 1,4 & 58 \\
& Ec & Azoxystrobin (200 g a.i./ha) & $2,3,5,6$ & 61 \\
\hline
\end{tabular}

${ }^{\mathrm{z}}$ Fungicide applications were initiated approximately 2 weeks before bloom in mid-June, and applied thereafter at 2-week intervals. 
bated at ambient room temperature (20 to $25^{\circ} \mathrm{C}$ ) with alternating 12 -h periods of fluorescent light and darkness.

Seven days after inoculation, mycelial expansion from the point of inoculation on each leaf disk was determined using a $32 x$ ocular micrometer and a stereomicroscope. Three measurements of radial expansion were made for each of the roughly circular colonies, and the mean values for the four replicate leaf disks per treatment were used to calculate the relative growth (RG values, average radial expansion of the check treatment) for each isolate $\times$ concentration combination. Dose response curves for individual isolates were generated by plotting the RG values against the $\log _{10}$ of the fungicide concentration used (Microsoft Excel 7.0, Seattle, WA), and the $\log _{10}$ effective doses for $50 \%$ growth inhibition of mycelial growth $\left(\log _{10} \mathrm{ED}_{50}\right.$ values) were calculated from the regression equation generated through the linear portion of the sigmoidal curve.

Assay reproducibility. To determine the reproducibility of the test, azoxystrobin and myclobutanil sensitivities were assayed five times for each of six isolates. Three isolates were chosen from both the baseline and DMI-resistant sites, to best represent the range of fungicide sensitivities among the sample population. For each repeat of the test, in which all six isolates were assayed, a new stock solution of either azoxystrobin or myclobutanil was prepared. The mean of the $\mathrm{ED}_{50}$ values, variance, coefficient of variance, and $95 \%$ confidence intervals were calculated for each isolate based upon the five replicated tests. Since $\mathrm{ED}_{50}$ values are typically lognormally distributed, the appropriate formulas $(4,13)$ were used to calculate these values using the natural $\log$ of the $\mathrm{ED}_{50}$ values (Table 2). A mean coefficient of variance was calculated for both the azoxystrobin and myclobutanil assays, based upon the results from these six isolates. The least significant difference $(\alpha=0.05)$ was calculated based upon the mean $\log _{10}$ $\mathrm{ED}_{50}$ values for the six isolates using single-factor analysis of variance and Fisher's
LSD (Minitab, v. 12.10, State College, PA).

Distributions of U. necator sensitivities to azoxystrobin and myclobutanil. After the assay reproducibility was known, the test was conducted once for each of the 256 isolates of $U$. necator. For each run of the experiment, approximately 10 isolates were assayed, employing solutions ranging from 0.0020 to $8.0 \mu \mathrm{g} / \mathrm{ml}$ for myclobutanil, and from 0.00049 to $2.0 \mu \mathrm{g} / \mathrm{ml}$ for azoxystrobin. New fungicide stock solutions were prepared after two runs of the test. Histograms were constructed for $\log _{10}$ $\mathrm{ED}_{50}$ values based upon the least significant difference among the fungicide sensitivities of the six isolates tested for assay reproducibility (approximately $0.20 \log _{10}$ units), as described above. Fungicide sensitivities between the baseline population and the unsprayed checks from the DMIresistant site (Bl versus Ec) were compared using Student's $t$ test (Minitab v. 12.10), using the unsprayed check population as a second baseline population for the comparison of fungicide sensitivities of isolates recovered from vines where no selection pressure for shifts in sensitivity was applied. Differences among the three populations from the DMI-resistant site were analyzed by ANOVA and Fisher's LSD (Minitab v. 12.10). Statistics were performed on the normally distributed $\log _{10^{-}}$ transformed $\mathrm{ED}_{50}$ values. $\log _{10} \mathrm{ED}_{50}$ values for azoxystrobin and myclobutanil of each individual isolate were correlated to determine if a relationship existed between azoxystrobin and myclobutanil sensitivities, examining all populations collectively and each individual population separately (Minitab v. 12.10). To determine if a single discriminatory dose could be used to accurately evaluate fungicide sensitivities, as has been suggested for evaluating $V$. inaequalis sensitivities to DMI fungicides (32), $\log _{10} \mathrm{ED}_{50}$ values were regressed against the RG values obtained for each isolate at $0.0078,0.031$, and $0.13 \mu \mathrm{g}$ of azoxystrobin per $\mathrm{ml}$ (MS Excel 7.0). Likewise, for myclobutanil, $\log _{10} \mathrm{ED}_{50}$ values were regressed against the RG val-

Table 2. Formulas used for calculations of assay reproducibility

\begin{tabular}{lll}
\hline Term & Formula & Reference \\
\hline Mean & $e^{\mu+\frac{\sigma^{2}}{2}}$ & Casella and Berger (4) \\
Variance & $e^{2\left(\mu+\sigma^{2}\right)}-e^{2 \mu+\sigma^{2}}$ & Casella and Berger (4) \\
Coefficient of variance & $\frac{e^{2\left(\mu+\sigma^{2}\right)}-e^{2 \mu+\sigma^{2}}}{e^{\mu+\frac{\sigma^{2}}{2}}}$ & Casella and Berger (4) \\
Confidence interval upper limit & $e^{\mu+\frac{\sigma^{2}}{2}+\frac{\sigma H_{1-\alpha}}{\sqrt{n-1}}}$ & Gilbert (13) \\
Confidence interval lower limit & $e^{\mu+\frac{\sigma^{2}}{2}+\frac{\sigma H_{\alpha}}{\sqrt{n-1}}}$ & Gilbert (13) \\
\hline
\end{tabular}

${ }^{\mathrm{z}} \mu$ and $\sigma^{2}$ are the mean and variance, respectively, of the natural $\log$ of the $\mathrm{ED}_{50}$ values of individual isolates determined from the leaf disk assays. $H_{1-\alpha}$ and $H_{\alpha}$ are the Land's coefficients used for calculating the upper and lower confidence intervals for a specified level of $\alpha$. ues obtained at $0.50 \mu \mathrm{g} / \mathrm{ml}$, a discriminatory dose used but not validated by a previous study (35).

Sensitivity of U. necator isolates to pyraclostrobin, kresoxim-methyl, and trifloxystrobin. To determine if our U. necator assay was applicable to strobilurin fungicides other than azoxystrobin, and to compare the relative intrinsic activities of these against $U$. necator, the technique was used to test 26 isolates spanning the range of sensitivities to azoxystrobin for their sensitivities to kresoxim-methyl, pyraclostrobin, and trifloxystrobin. Fungicide solutions ranged in concentration from 0.00012 to $8.0 \mu \mathrm{g} / \mathrm{ml}$ for kresoxim-methyl and from 0.00012 to $0.50 \mu \mathrm{g} / \mathrm{ml}$ for pyraclostrobin and trifloxystrobin. Histograms based upon the $\log _{10} \mathrm{ED}_{50}$ values were constructed, and differences in the sensitivities of these isolates to azoxystrobin, kresoxim-methyl, pyraclostrobin, and trifloxystrobin were analyzed by ANOVA and Fisher's LSD (Minitab v. 12.10). Regression analysis was used to compare the $\log _{10} \mathrm{ED}_{50}$ values of individual isolates for each of the fungicides (Minitab v. 12.10).

Influence of azoxystrobin sensitivity differences on disease control. To determine if the differences in sensitivity to azoxystrobin detected among $U$. necator isolates have practical implications with respect to disease control, a seedling assay was utilized to test the effect of different azoxystrobin dosages against a composite of five isolates of high sensitivity (B1-5, $38,65,84,85 ;$ mean $\left.\mathrm{ED}_{50}=0.0040 \mu \mathrm{g} / \mathrm{ml}\right)$ versus a composite of five isolates of low sensitivity (Em-17, 45, 47, 48, 63; mean $\left.\mathrm{ED}_{50}=0.061 \mu \mathrm{g} / \mathrm{ml}\right)$. The seedling bioassay was based upon previous work investigating the physical mode of action of azoxystrobin against $P$. viticola (38). Bioassays with $U$. necator were performed using azoxystrobin in both protectant and postinfection modes. For each run of the protectant assays, sets of six replicate 6week-old $V$. vinifera $\mathrm{cv}$. Riesling seedlings, each having four to five true leaves, were sprayed until runoff 1 day before inoculation with commercially formulated azoxystrobin (Abound $2.08 \mathrm{~F}$ ) at concentrations of $0,0.25,2.5,25$, and $250 \mu \mathrm{g}$ a.i./ml, using a modified paint sprayer at a pressure of $207 \mathrm{kPa}$. To facilitate their subsequent identification, the first three leaves larger than $2.5 \mathrm{~cm}$ in diameter were marked with small strips of tape around the petioles; then fungicide solutions were applied until runoff.

To prepare the inoculum, five surfacedisinfested leaf sections (approximately 30 $\times 60 \mathrm{~mm}$ ) kept on $1.5 \%$ water agar in 60 $\mathrm{mm}$ petri dishes were inoculated with several chains of conidia from individual $U$. necator isolates, one set of five leaves for each individual isolate. Leaf sections were incubated at room temperature as described above. Two weeks later, three infected leaf sections (those with the most abundant 
sporulation) for each isolate from either the high or the low sensitivity group were placed into a 50-ml screw-top centrifuge tube containing $25 \mathrm{ml}$ of $0.0005 \%$ Tween 20 in type $\mathrm{I}_{2} \mathrm{O}$, and vortexed for $30 \mathrm{~s}$ (total of 15 leaf sections per treatment). The conidial suspension was adjusted to a final concentration of $5 \times 10^{5}$ conidia per $\mathrm{ml}$ with additional $0.0005 \%$ Tween 20 in type $\mathrm{I}_{2} \mathrm{O}$. Seedlings were inoculated immediately thereafter by spraying the conidial suspension from a height of $1 \mathrm{~m}$ in a fine mist using a modified paint gun (at $207 \mathrm{kPa}$ ). Tests using the two different sensitivity groups were performed on different dates to minimize the effect of crossinterference between groups. Each seedling received a 5-s misting, in which approximately $2.5 \times 10^{5}$ conidia were sprayed onto the plant. The mist droplets dried quickly, usually within 5 to $10 \mathrm{~min}$. Thirty minutes after inoculation, seedlings were moved to a greenhouse and transferred into customized $1 \times 1 \times 1.5 \mathrm{~m}(\mathrm{~W} \times \mathrm{L} \times \mathrm{H})$ Plexiglas containment chambers, each with its own source of HEPA-filtered air to minimize the probability of contamination from other $U$. necator sources. Seedlings were incubated at $25^{\circ} \mathrm{C}$ for 14 days with ambient lighting; then disease severity on the three marked leaves was determined by overlaying a $100-\mathrm{mm}$ plastic petri plate, marked with a $1 \times 1 \mathrm{~cm}$ grid above (but not contacting) the leaves, and determining both the diseased and total surface area of the leaf.

To test the postinfection activity of azoxystrobin against the two sensitivity groups, the same procedures were used, except that untreated seedlings were inoculated and placed into the containment chambers after a 30-min drying period. Five days after inoculation, when colonies on the leaves could be visually detected, seedlings were removed from the chambers, sprayed with the same concentration range of azoxystrobin, then allowed to airdry for $2 \mathrm{~h}$ before being returned to the containment chambers. Disease was assessed 14 days after inoculation, as described above. Each experiment was conducted three times, using six replicate seedlings per treatment. Disease severity data were normalized using the arcsine $\sqrt{y}$ transformation, and the means of each replicate set of six seedlings were analyzed by multivariate ANOVA using the general linear model procedure of SAS (SAS 6.0, SAS Institute, Cary, NC). The sum of squares was partitioned using orthogonal contrasts to determine the levels of significance and main sources of variation for the treatment interactions. Additional Student's $t$ tests were performed to compare disease severity data between the low- and highsensitivity groups for each concentration of azoxystrobin used (Minitab v. 12.10) for both protectant and postinfection assays.

\section{RESULTS}

Fungicide sensitivity assays. Assay reproducibility. For the six isolates examined in five repeated runs of the assay, the coefficients of variance for each isolate ranged from 10 to $29 \%$ with respect to azoxystrobin assays and from 11 to $126 \%$ with respect to myclobutanil assays. The mean coefficients of variance for these assays were 31 and $41 \%$, respectively (Table 3 ). The $95 \%$ confidence intervals ranged from 62 to $268 \%$ and from 47 to $1099 \%$ of the mean $\mathrm{ED}_{50}$ values for individual isolates subjected to the azoxystrobin and myclobutanil assays, respectively (Table $3)$. On average, the $95 \%$ confidence intervals ranged from 76 to $293 \%$ and 79 to $154 \%$ of the mean values, respectively, for azoxystrobin and myclobutanil assays. The least significant difference $(\alpha=0.05)$ separating mean $\mathrm{ED}_{50}$ values beyond that attributable to experimental error was 0.17 and $0.23 \log _{10}$ units, respectively, for the azoxystrobin and myclobutanil assays.

Baseline distribution of $\mathrm{U}$. necator sensitivities to azoxystrobin and myclobutanil. Among the isolates from the baseline population $(\mathrm{Bl})$, individual $\mathrm{ED}_{50}$ values for azoxystrobin ranged from 0.0037 to 0.028 $\mu \mathrm{g} / \mathrm{ml}$ (separated by a factor of 7.5), with a mean value of $0.0097 \mu \mathrm{g} / \mathrm{ml}$ (Fig. 1A). In comparison, there was an approximate twofold difference in the mean azoxystrobin $\mathrm{ED}_{50}$ value of isolates recovered from the unsprayed checks from the DMIresistant population $(\mathrm{Ec})$, with individual values for the 61 isolates ranging from 0.0034 to $0.048 \mu \mathrm{g} / \mathrm{ml}$ (separated by a factor of 14), with a mean of $0.018 \mu \mathrm{g} / \mathrm{ml}$ (Fig. 1A). The mean $\log _{10} \mathrm{ED}_{50}$ values of these two sensitivity distributions were significantly different according to Stu- dent's $t$ test $(P<0.001)$. Furthermore, the difference in the mean $\log _{10} \mathrm{ED}_{50}$ values for these populations $(0.27)$ exceeded the least significant difference value of 0.17 $\log _{10}$ units of the assay, indicating that the observed differences were not merely due to any imprecision in repeated assays.

For myclobutanil sensitivities, individual $\mathrm{ED}_{50}$ values for isolates from the baseline population ranged from 0.0049 to 0.69 $\mu \mathrm{g} / \mathrm{ml}$ (mean $=0.075 \mu \mathrm{g} / \mathrm{ml}$ ), being separated by a factor of approximately 140 (Fig. 1B). These results are similar to those previously reported from the same location in 1995 (10). Individual $\mathrm{ED}_{50}$ values for isolates recovered from the unsprayed vines from the DMI-resistant site ranged from 0.021 to $3.7 \mu \mathrm{g} / \mathrm{ml}$ (separated by a factor of approximately 180), with a mean value of $0.92 \mu \mathrm{g} / \mathrm{ml}$. This 12 -fold difference in mean $\mathrm{ED}_{50}$ values was significant $(P<0.001)$ according to Student's $t$ test. Even more pronounced was the difference in sensitivities between the median categories for the two populations, whose midpoint values were separated by a factor of nearly 30 (Fig. 1B).

Field performance of azoxystrobin and myclobutanil and sensitivity shifts over a single season. For the 1999 season, the myclobutanil and azoxystrobin-myclobutanil spray programs at the Dresden site, where the DMI-resistant population was collected, provided 86 and $91 \%$ control of disease caused by $U$. necator, respectively, based upon the severity of cluster infections during a year of low disease pressure. In contrast, data from 1998 (when disease pressure was higher) showed 63 and 93\% control under the same experimental treatments. Differences between these two treatments were only significant for the 1998 growing season (Duncan-Waller $k$ test, $\alpha=0.05$, W. F. Wilcox, unpublished). In 1996 and 1997, where azoxystrobin was absent from the spray programs, only 84 and $76 \%$ control of disease was obtained, respectively, when myclobutanil was used exclusively during the growing season (W. F. Wilcox, unpublished).

Of the individual isolates from the DMIresistant population, those from subpopulation Em (six myclobutanil sprays) had the lowest sensitivity to azoxystrobin, with a mean $\mathrm{ED}_{50}$ value of $0.024 \mu \mathrm{g} / \mathrm{ml}$ and a

Table 3. Reproducibility of assay for determining $\mathrm{ED}_{50}$ values for azoxystrobin and myclobutanil against six isolates of Uncinula necator

\begin{tabular}{|c|c|c|c|c|c|c|}
\hline \multirow[b]{2}{*}{ Isolate } & \multicolumn{3}{|c|}{$\mathrm{ED}_{50}(\mu \mathrm{g} / \mathrm{ml})$ azoxystrobin } & \multicolumn{3}{|c|}{$\mathrm{ED}_{50}(\mu \mathrm{g} / \mathrm{ml})$ myclobutanil } \\
\hline & $\operatorname{Mean}^{x}$ & $95 \% \mathrm{CI}^{\mathrm{y}}$ & $\mathbf{C V}^{\mathbf{z}}$ & $\operatorname{Mean}^{x}$ & $95 \% \mathrm{CI}^{\mathrm{y}}$ & $\mathbf{C V}^{\mathrm{z}}$ \\
\hline Bl-1 & 0.008 & $(0.007-0.011)$ & 0.22 & 0.015 & $(0.012-0.024)$ & 0.33 \\
\hline Bl-3 & 0.016 & $(0.013-0.023)$ & 0.29 & 0.058 & $(0.027-0.632)$ & 1.26 \\
\hline B1-6 & 0.011 & $(0.009-0.014)$ & 0.22 & 0.012 & $(0.009-0.018)$ & 0.35 \\
\hline Em-3 & 0.013 & $(0.010-0.020)$ & 0.35 & 1.304 & $(1.168-1.477)$ & 0.12 \\
\hline Em-4 & 0.024 & $(0.015-0.065)$ & 0.66 & 1.499 & $(1.359-1.675)$ & 0.11 \\
\hline Em-5 & 0.013 & $(0.012-0.014)$ & 0.10 & 0.619 & $(0.497-0.848)$ & 0.27 \\
\hline Mean & & & 0.31 & & & 0.41 \\
\hline
\end{tabular}

${ }^{\mathrm{x}}$ Mean $\mathrm{ED}_{50}$ value based upon $\log _{e}$-transformed $\mathrm{ED}_{50}$ values obtained from five repeated assays.

y $95 \%$ confidence interval based upon $\log _{e}$-transformed $\mathrm{ED}_{50}$ values.

${ }^{\mathrm{z}}$ The coefficient of variance based upon $\log _{e}$-transformed $\mathrm{ED}_{50}$ values. 
range of 0.0047 to $0.075 \mu \mathrm{g} / \mathrm{ml}$ (Fig. 2A). In contrast, isolates from the azoxystrobinmyclobutanil spray program (Ea) had a mean $\mathrm{ED}_{50}$ of $0.015 \mu \mathrm{g} / \mathrm{ml}$ (range $=0.0046$ to $0.033 \mu \mathrm{g} / \mathrm{ml}$ ). Analysis of variance for the three subpopulations indicated that differences among subpopulations were significant $(P<0.001)$, and multiple comparisons indicated that sensitivities of isolates from the Ea and Ec populations were similar to each other but significantly different from those from the Em population (Fisher's LSD, $\alpha=0.05$ ).

Within the DMI-exposed subpopulations, isolates recovered from vines subjected to six myclobutanil sprays (Em) were even less sensitive to myclobutanil than were isolates from unsprayed vines (Ec) or those treated with the azoxystrobin-myclobutanil rotation (Ea), as evidenced by an increased value for the midpoint of the median sensitivity category and differences in mean $\mathrm{ED}_{50}$ values (1.2, 0.91 , and $0.92 \mu \mathrm{g} / \mathrm{ml}$, respectively) (Fig. 2B). Analysis of variance indicated that the differences among subpopulations were significant $(P<0.001)$, and multiple comparisons indicated that the mean sensitivities of isolates from subpopulations Ea and Ec were similar but significantly different from those of subpopulation Em (Fisher's LSD, $\alpha=0.05$ ).
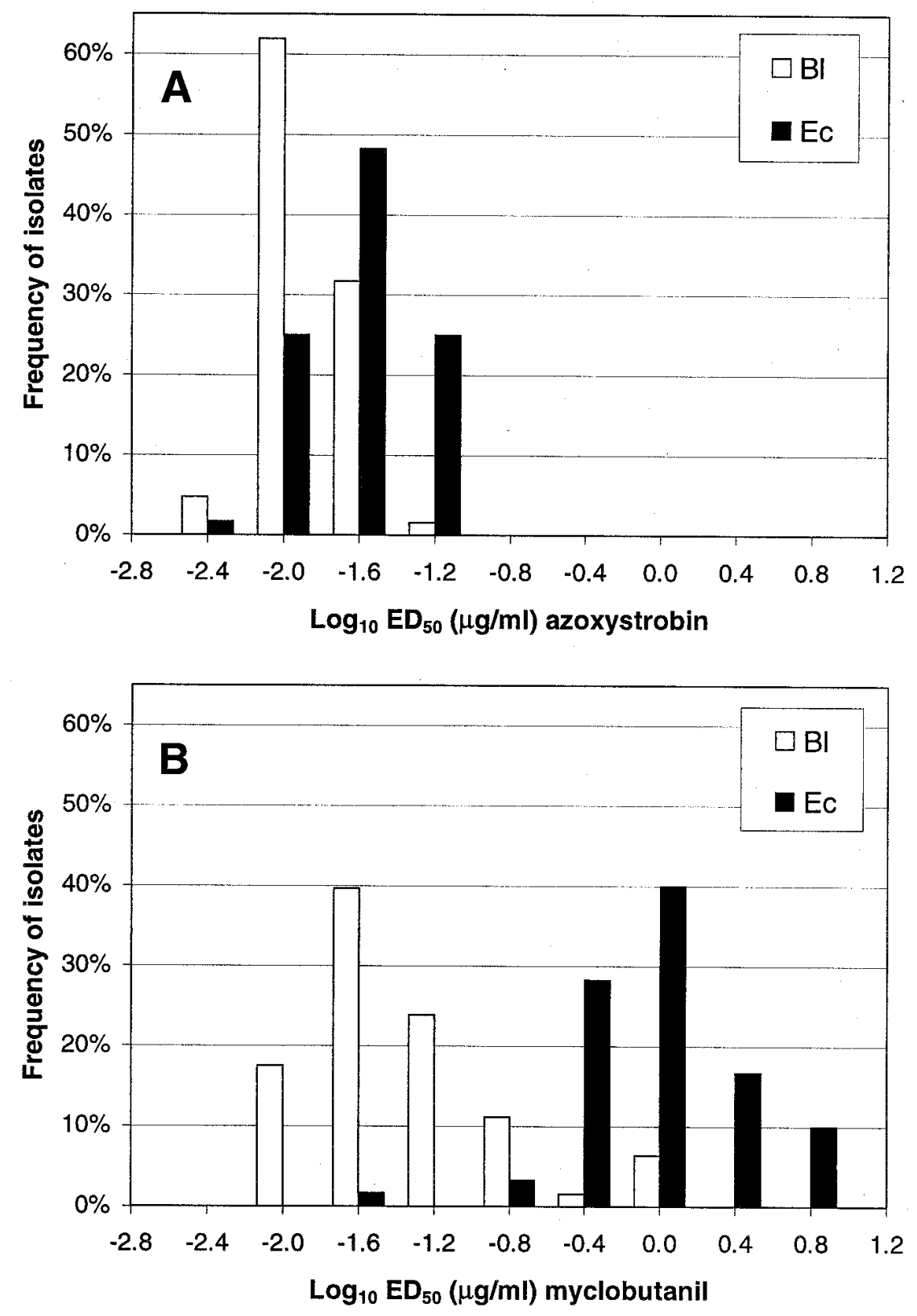

Fig. 1. Distribution of sensitivities for isolates of Uncinula necator collected from a site previously unexposed to either demethylation inhibitor (DMI) or strobilurin fungicides $(\mathrm{Bl}, \mathrm{n}=68)$ and the unsprayed check vines from a DMI-resistant site $(\mathrm{Ec}, \mathrm{n}=61) \mathbf{A}$, azoxystrobin and $\mathbf{B}$, myclobutanil. Discreet categories of $\mathrm{ED}_{50}$ values for individual isolates are organized based upon the least significant difference of $0.20 \log _{10}$ units $(\alpha=0.05)$. Indicated values represent the midpoint for each sensitivity category.

Cross-sensitivity to azoxystrobin and myclobutanil among isolates of $\mathrm{U}$. necator. Regression analysis of $\log _{10}$-transformed $\mathrm{ED}_{50}$ values for azoxystrobin and myclobutanil for all 256 isolates indicated a moderate but highly significant linear relationship between sensitivities to these two fungicides (Fig. 3A). However, when the baseline population and the individual subpopulations from the DMI-resistant site were analyzed separately, it was apparent that this relationship was most pronounced among isolates that had been subjected to intensive selection pressure for tolerance to myclobutanil (Fig. 3C), and not evident in other treatments.

Relative aggressiveness of $\mathrm{U}$. necator isolates with respect to azoxystrobin and myclobutanil sensitivities. To determine if sensitivities to either azoxystrobin or myclobutanil were related to the aggressiveness of individual isolates, $\log _{10^{-}}$ transformed $\mathrm{ED}_{50}$ values for each fungicide were regressed against the mean radial expansion on the untreated (check) leaf disks for all 256 isolates. Regression analysis indicated no linear relationship between colony expansion and azoxystrobin sensitivity $\left(R^{2}=0.001, P=0.690\right)$ and only a very weak negative linear relationship between colony expansion and myclobutanil sensitivity $\left(R^{2}=0.018, P=\right.$ 0.028).

Validity of single discriminatory doses for determining U. necator sensitivities to azoxystrobin and myclobutanil. There was a strong linear relationship between RG values obtained at the tested discriminatory dose concentrations of $0.031 \mu \mathrm{g} / \mathrm{ml}$ for azoxystrobin and $0.50 \mu \mathrm{g} / \mathrm{ml}$ for myclobutanil and the $\log _{10} \mathrm{ED}_{50}$ values with respect to individual $U$. necator isolates (Fig. 4). For the three discriminatory doses of azoxystrobin analyzed, the RG values obtained at $0.031 \mu \mathrm{g} / \mathrm{ml}$ appeared to be more appropriate for estimating useful $\log _{10} \mathrm{ED}_{50}$ values. For RG values determined for azoxystrobin at $0.031 \mu \mathrm{g} / \mathrm{ml}$, the regression line was described by the equation: $\log _{10}$ $\mathrm{ED}_{50 \text { (azoxystrobin) }}=1.23(\mathrm{RG})-2.19\left(R^{2}=\right.$ $0.64, P<0.001)$. The range of $\mathrm{ED}_{50}$ values that could be calculated based upon this equation would be 0.0064 to $0.11 \mu \mathrm{g} / \mathrm{ml}$. Likewise, for calculating $\mathrm{ED}_{50}$ values based upon the RG values for myclobutanil at $0.50 \mu \mathrm{g} / \mathrm{ml}$, the relationship was described by: $\log _{10} \quad \mathrm{ED}_{50 \text { (myclobutanil) }}=$ $2.17(\mathrm{RG})-1.62\left(R^{2}=0.81, P<0.001\right)$. The range of $\mathrm{ED}_{50}$ values that could be calculated based upon the RG values at this dose of myclobutanil would be 0.024 to 3.5 $\mu \mathrm{g} / \mathrm{ml}$.

Sensitivity of selected U. necator isolates to pyraclostrobin, kresoxim-methyl, and trifloxystrobin. Similar leaf disk assays of $P$. viticola sensitivities to strobilurin fungicides indicated that this technique was better suited for tests with azoxystrobin than for tests with kresoxim-methyl and trifloxystrobin (37). Within its limitations, 
the technique indicated substantial differences among the intrinsic activities of the three strobilurins against this pathogen. The leaf disk assay was applicable to all strobilurin fungicides tested except kresoxim-methyl. $\mathrm{ED}_{50}$ values for kresoxim-methyl could not be calculated for all of the isolates tested due to a combination of the phytotoxicity of the compound to leaf disks at concentrations $\geq 4.0$ $\mu \mathrm{g} / \mathrm{ml}$ and its relatively low intrinsic activity against $U$. necator (Fig. 5). As seen in previous work (37), trifloxystrobin caused similar phytotoxicity on leaf disks at concentrations $\geq 0.5 \mu \mathrm{g} / \mathrm{ml}$, but its intrinsic activity against $U$. necator was sufficient to allow the determination of $\mathrm{ED}_{50}$ values when used in the assays at lower, nonphytotoxic concentrations.

Pyraclostrobin had the highest intrinsic activity of the four strobilurin fungicides tested, with individual $\mathrm{ED}_{50}$ values for the 26 isolates tested ranging from 0.0016 to $0.010 \mu \mathrm{g} / \mathrm{ml}$, with a mean value of 0.0044 $\mu \mathrm{g} / \mathrm{ml}$ (Fig. 5). For trifloxystrobin, individual $\mathrm{ED}_{50}$ values ranged from 0.0058 to $0.052 \mu \mathrm{g} / \mathrm{ml}$, with a mean value of 0.015 $\mu \mathrm{g} / \mathrm{ml}$ (Fig. 5). Azoxystrobin sensitivities ranged from 0.0042 to $0.055 \mu \mathrm{g} / \mathrm{ml}$, with a mean value of $0.013 \mu \mathrm{g} / \mathrm{ml}$ (Fig. 5). Analy-
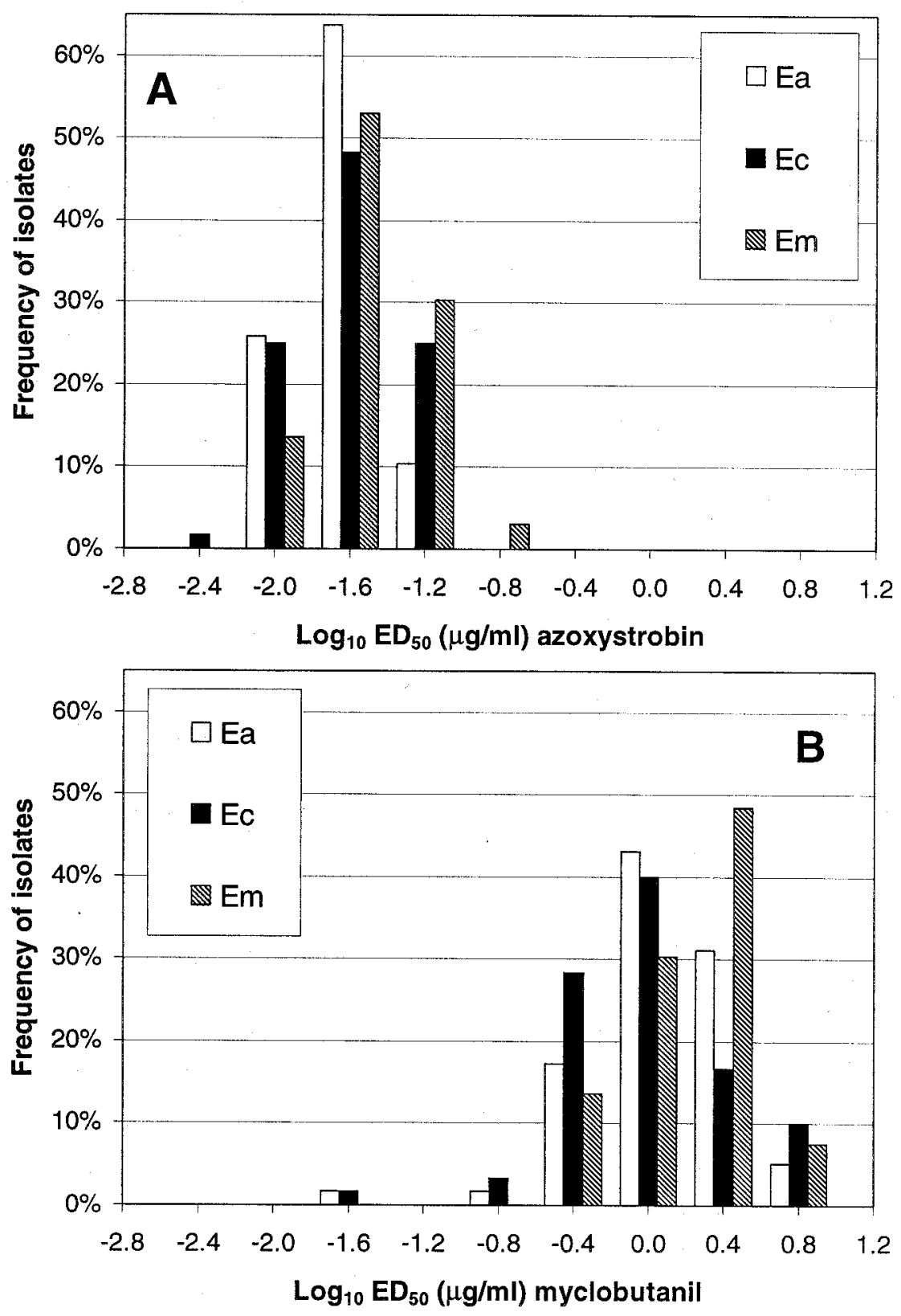

Fig. 2. Distribution of sensitivities to azoxystrobin and myclobutanil among isolates of Uncinula necator exposed to different experimental treatments from a demethylation inhibitor (DMI)-resistant site. Distribution of sensitivities for the DMI-resistant subpopulations, Ea (azoxystrobin and myclobutanil in rotation, $\mathrm{n}=58$ ), Ec (unsprayed, $\mathrm{n}=61$ ), and Em (six myclobutanil applications, $\mathrm{n}=69$ ) for $\mathbf{A}$, azoxystrobin and $\mathbf{B}$, myclobutanil. Discreet categories of $\mathrm{ED}_{50}$ values for individual isolates are organized based upon the least significant difference of $0.20 \log _{10}$ units $(\alpha=0.05)$. Indicated values represent the midpoint for each sensitivity category.

sis of variance and multiple comparisons indicated that mean $\mathrm{ED}_{50}$ values for azoxystrobin and trifloxystrobin were not statistically different from each other, but both were statistically different compared with pyraclostrobin (Fisher's LSD, $\alpha=0.05$ ).

There was a strong correlation between azoxystrobin and trifloxystrobin $\log _{10} \mathrm{ED}_{50}$ values $\left(R^{2}=0.75, P<0.001\right)$ (Fig. 6A). However, $\log _{10} \mathrm{ED}_{50}$ values for pyraclostrobin did not correlate as well with those of azoxystrobin $\left(R^{2}=0.21, P=0.018\right)$ or trifloxystrobin $\left(R^{2}=0.24, P=0.010\right)$ (Fig. $6 \mathrm{~B}$ and $\mathrm{C})$.

Influence of azoxystrobin sensitivity on disease control. Within the relatively narrow range of azoxystrobin sensitivities that we detected in our field samples of $U$. necator, differences affected disease control only when the fungicide was used at fractions of the recommended rate, and effects on disease control were more pronounced when it was used in a postinfection rather than a protective mode. Protectant applications provided $100 \%$ control of the composite populations of both high and low sensitivity at the recommended rate of $250 \mu \mathrm{g}$ a.i./ml and also at $10 \%$ of this rate (Fig. 7A). When seedlings were treated

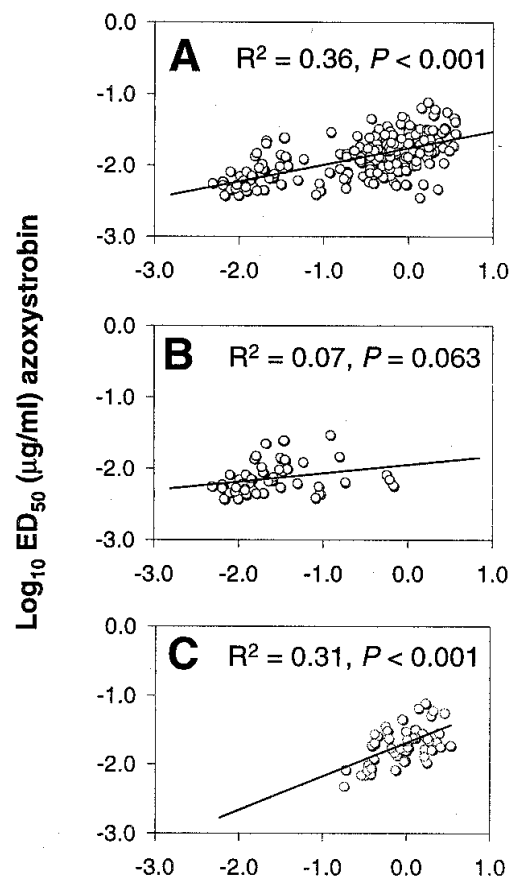

$\log _{10} E_{50}(\mu \mathrm{g} / \mathrm{ml})$ myclobutanil

Fig. 3. Relationship between sensitivities to azoxystrobin and myclobutanil among individual isolates of Uncinula necator. The coefficients of determination and significance levels are shown for the equations derived from regressing the $\log _{10} \mathrm{ED}_{50}$ values for azoxystrobin on $\log _{10} \mathrm{ED}_{50}$ values for myclobutanil for $\mathbf{A}$, all tested isolates $(\mathrm{n}=256), \mathbf{B}$, all isolates from the baseline population $(n=68)$, and $\mathbf{C}$, all isolates from subpopulation Em (six myclobutanil applications, $\mathrm{n}=69$ ). 
with $2.5 \mu \mathrm{g}$ a.i./ml azoxystrobin, control of the low-sensitivity isolates was $73 \%$, as opposed to $91 \%$ for the high-sensitivity group. At a rate of $0.25 \mu \mathrm{g}$ a.i./ml, control of the low- and high-sensitivity groups was 26 and $39 \%$, respectively. Analysis of variance indicated a significant difference between the response of the low- and highsensitivity isolates against the four rates of azoxystrobin (Fig. 7A, Table 4). However, pairwise comparisons of disease development between groups indicated no significant differences for the control of either group at any given rate (Student's $t$ test, $\alpha$ $=0.05$ ) (Fig. 7A). Analysis of variance indicated no significant difference between the runs of the experiments $(P=0.90)$, indicating that the analysis of the means of the treatments in three replicated experiments was statistically appropriate.

In contrast, although postinfection applications of azoxystrobin provided virtually complete control of both $U$. necator populations at the $250 \mu \mathrm{g}$ a.i./ml rate, such applications at lower rates were pronouncedly less effective against isolates of low versus high sensitivity to the fungicide. For example, whereas a rate of $25 \mu \mathrm{g}$ a.i./ml provided $98 \%$ control of the highsensitivity group, it provided only 54\% control for the low-sensitivity groups. Similarly, there was a $41 \%$ difference be-

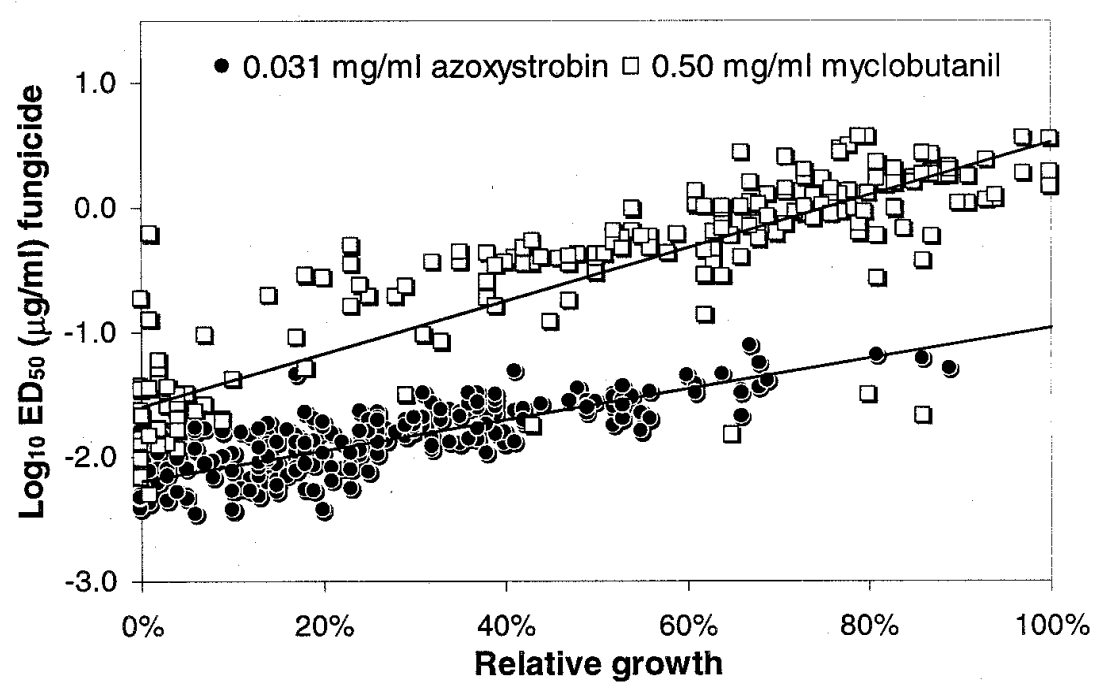

Fig. 4. Relationship between the relative growth (compared with the check treatment) of individual isolates of Uncinula necator on grape leaf disks treated with a single discriminatory dose of azoxystrobin at $0.0078 \mu \mathrm{g} / \mathrm{ml}$ or myclobutanil at $0.50 \mu \mathrm{g} / \mathrm{ml}$ and the $\log _{10} \mathrm{ED}_{50}$ values determined for the same isolates for each respective fungicide. tween these groups with respect to disease severity following treatment with $2.5 \mu \mathrm{g}$ a.i./ml (Fig. 7B). Such differences are also reflected in the comparative analyses of variance for the protectant versus postinfection (Table 4) assays, e.g., the main effect of pathogen sensitivity and the interactive effect of sensitivity $\times$ fungicide concentration were both far greater under postinfection conditions. Individual comparisons between high- and low-sensitivity groups at each concentration of azoxystrobin used, using Student's $t$ tests, indicated no significant differences between the two sensitivity groups except for the 0.25 and $25 \mu \mathrm{g}$ a.i./ml treatments in the postinfection assay $(P=0.015$ and 0.012 , respectively) (Fig. 7B). Similar to the results for the protectant assays, differences between repeated runs of the experiment were not significant $(P=0.25)$, and analysis of the means of the treatments across the three experiments was statistically appropriate.

\section{DISCUSSION}

In this study, the baseline sensitivity of $U$. necator to azoxystrobin has been described, and according to the sample size of $68,95 \%$ of all isolates will fall into the described baseline sensitivity range with 95\% confidence (26). Based upon the composite population of baseline and DMI-resistant isolates, where limited applications of azoxystrobin have been used, the sample size of 256 isolates (with azoxystrobin $\mathrm{ED}_{50}$ values ranging from 0.0034 to $0.075 \mu \mathrm{g} / \mathrm{ml}$ and a mean of $0.017 \mu \mathrm{g} / \mathrm{ml}$ ) would represent between 98 and $99 \%$ of all isolates with $95 \%$ confidence (26). The narrow distribution of azoxystrobin sensitivities is similar to those previously de-

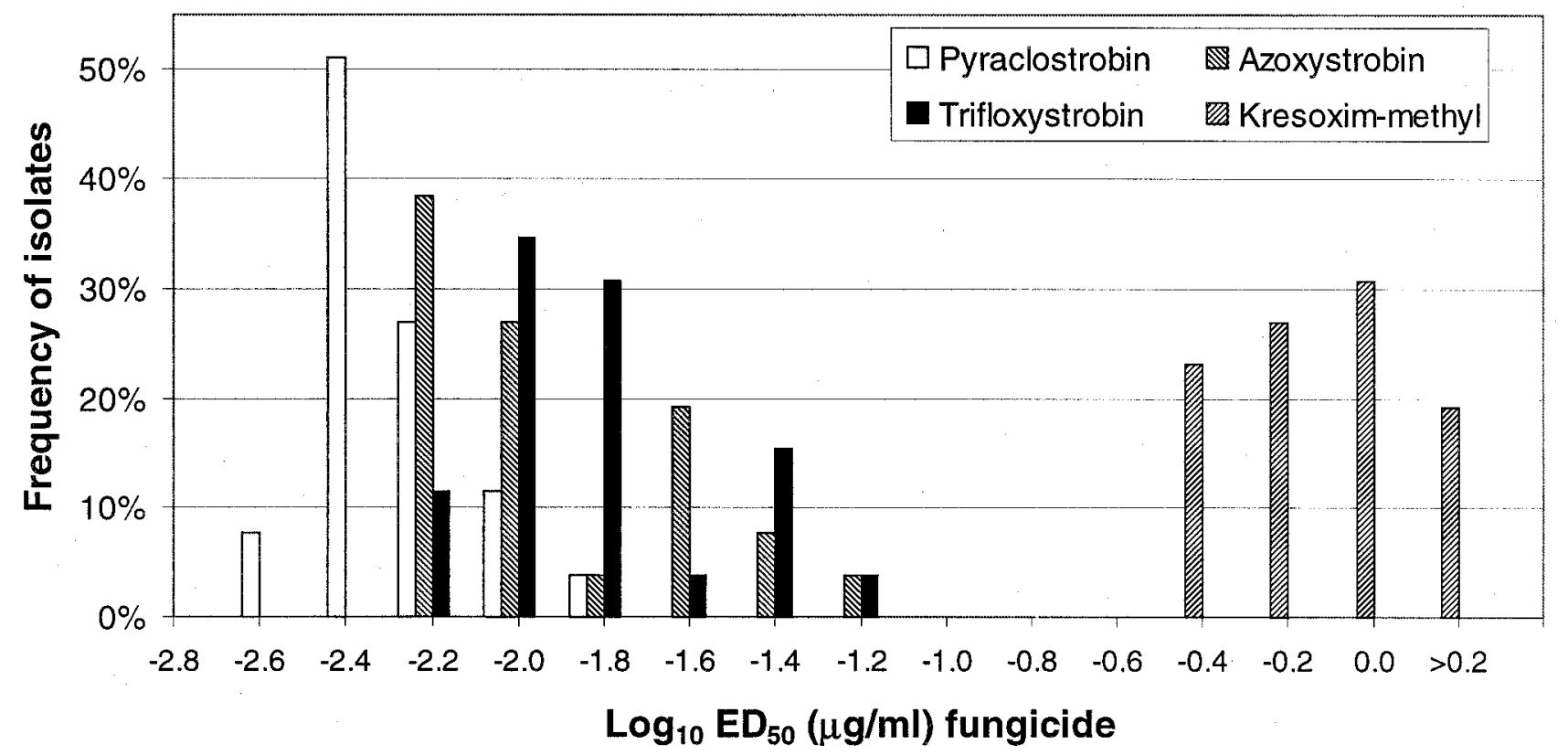

Fig. 5. Distribution of sensitivities to azoxystrobin, kresoxim-methyl, pyraclostrobin, and trifloxystrobin among 26 selected isolates of Uncinula necator. Discreet categories of $\mathrm{ED}_{50}$ values for individual isolates are organized based upon the least significant difference of $0.20 \log _{10}$ units $(\alpha=0.05)$. Indicated values represent the midpoint for each sensitivity category. 
scribed for Mycosphaerella graminicola (14) and P. viticola (37) to azoxystrobin and $V$. inaequalis to kresoxim-methyl $(29,30)$, and are in clear contrast with the much broader distribution of sensitivities to DMI fungicides documented in this and other $(10,16,40)$ studies on $U$. necator.

For future monitoring of $U$. necator sensitivities to azoxystrobin, the use of a single discriminatory dose of $0.031 \mu \mathrm{g} / \mathrm{ml}$ would be useful for characterizing isolates within the range of sensitivities detected for the 256 isolates of $U$. necator used in this study. However, isolate sensitivities outside of this range, which may include those that may develop qualitative resistance to azoxystrobin, would not be adequately discriminated, mandating that an additional higher discriminatory dose be used. The discriminatory dose of $2.0 \mu \mathrm{g} / \mathrm{ml}$ could suffice; only 18 of the 256 isolates tested grew at this concentration, with growth being $2 \%$ or less relative to the untreated check. Isolates that were not inhibited by this higher dose of azoxystrobin would be likely to have qualitative

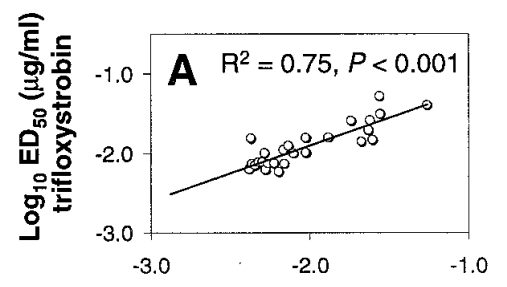

$\log _{10} E_{50}(\mu \mathrm{g} / \mathrm{ml})$ azoxystrobin

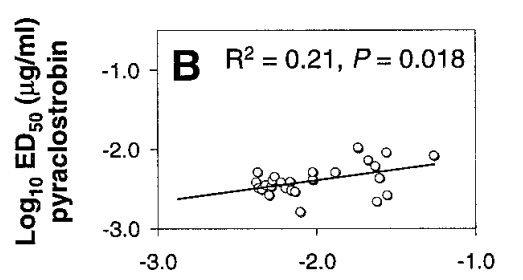

$\log _{10} \mathrm{ED}_{50}(\mu \mathrm{g} / \mathrm{ml})$ azoxystrobin

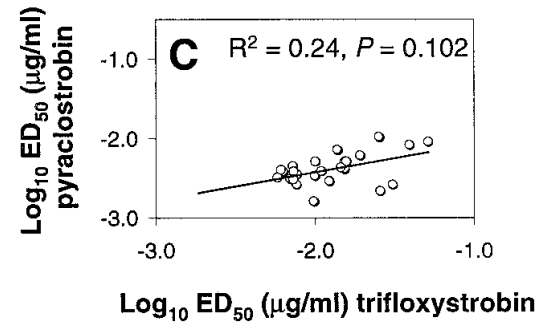

Fig. 6. Relationships among sensitivities to azoxystrobin, pyraclostrobin, and trifloxystrobin among 26 selected isolates of Uncinula necator. The coefficients of determination and significance levels are shown for the equations derived from regressing $\mathbf{A}, \log _{10} \mathrm{ED}_{50}$ values for trifloxystrobin on $\log _{10} \mathrm{ED}_{50}$ values for azoxystrobin, $\mathbf{B}, \log _{10} \mathrm{ED}_{50}$ values for pyraclostrobin on $\log _{10} \mathrm{ED}_{50}$ values for azoxystrobin, and $\mathbf{C}, \log _{10} \mathrm{ED}_{50}$ values for pyraclostrobin on $\log _{10} \mathrm{ED}_{50}$ values for trifloxystrobin. resistance to this fungicide. Since no isolates with this phenotype were detected in this study, additional work would have to be performed to confirm the presence of resistance, but this higher dose would appear to be a logical choice for a discriminatory dose that would allow for the detection of highly resistant isolates.

In contrast, the single discriminatory dose of $0.50 \mu \mathrm{g} / \mathrm{ml}$ appears to be applicable for future monitoring of $U$. necator sensitivities to myclobutanil. Relative growth values at this dose could be used to classify isolates representing a wide range of sensitivities as either myclobutanil sensitive or resistant (10).

The results of the comparative study of $U$. necator sensitivities to azoxystrobin, kresoxim-methyl, pyraclostrobin, and tri- floxystrobin illustrate a number of points. Kresoxim-methyl appeared to be several magnitudes lower in intrinsic activity compared with azoxystrobin, pyraclostrobin, and trifloxystrobin. However, kresoximmethyl has been shown to provide very good control of grapevine powdery mildew in the field $(33,34,36)$, indicating that the intrinsic activity of these strobilurin fungicides as determined by the excised leaf disk assay does not fully reflect the field performance of the fungicides. These results, in combination with a previous study on $P$. viticola and strobilurin fungicides (38), indicate that other physical properties of fungicides (vapor activity, redistribution, absorption, breakdown, etc.), in addition to intrinsic activity, contribute to the efficacy of a fungicide under field condi-
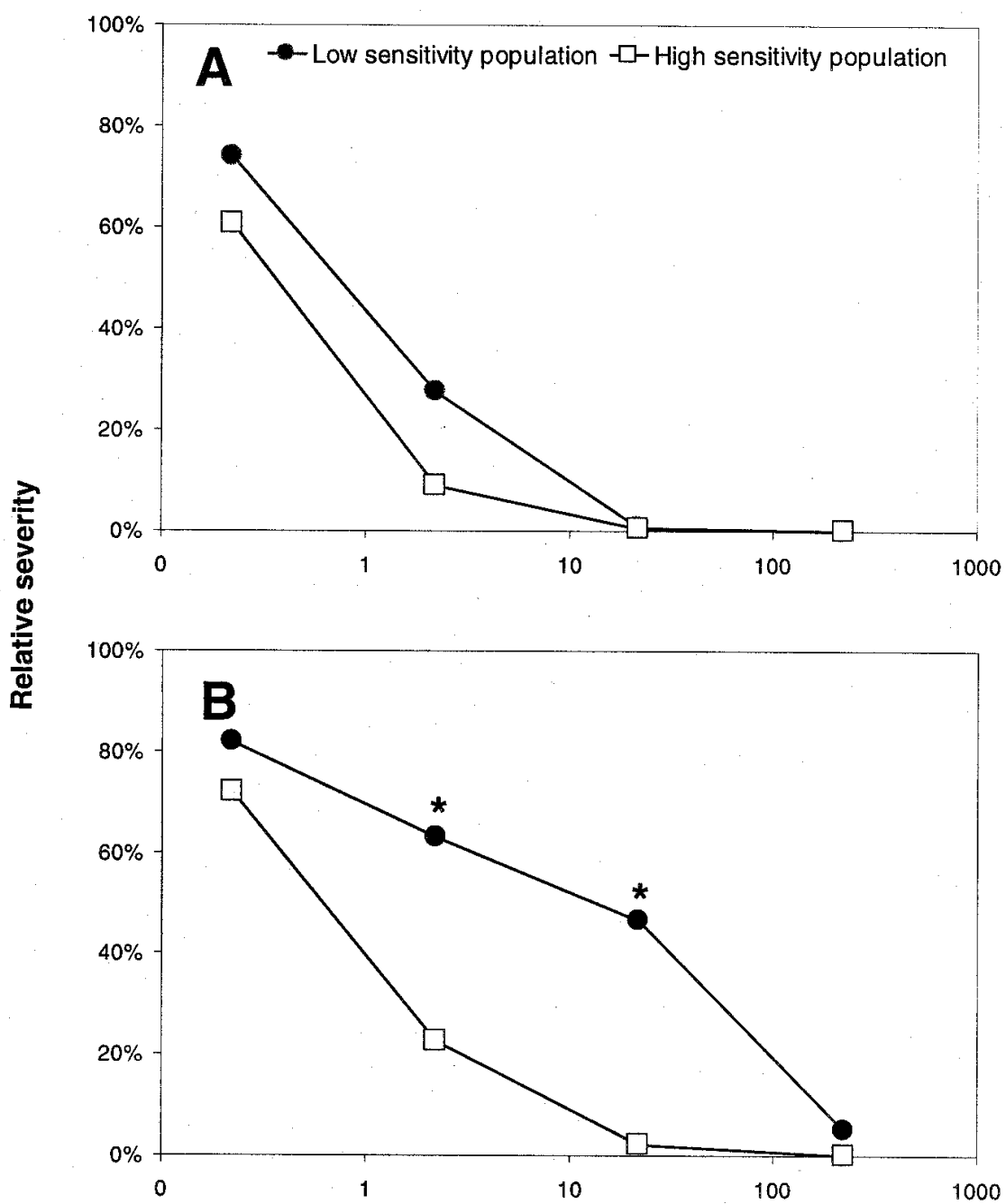

\section{Concentration of azoxystrobin $(\mu \mathrm{g} \mathrm{a.i} / \mathrm{ml})$}

Fig. 7. Disease control provided by azoxystrobin on Vitis vinifera $\mathrm{cv}$. Riesling seedlings inoculated with two composite populations of Uncinula necator with differing sensitivities to the fungicide (mean $\mathrm{ED}_{50}$ values $=0.0040$ and $0.061 \mu \mathrm{g} / \mathrm{ml}$, respectively). Disease severity is expressed as the percent surface area infected on the leaves of fungicide-treated relative to that on the $\mathrm{dH}_{2} \mathrm{O}$-treated checks, 14 days after inoculation. Each data point represents the mean value for 54 rated leaves over three replicated runs of the experiment. A, Seedlings were treated with fungicide 1 day before inoculation. B, Seedlings were treated with fungicide 5 days after inoculation. Significant differences (Student's $t$ test, $\alpha<0.05$ ) between high- and low-sensitivity populations within individual treatments are designated by $(*)$. 
tions, although the contributions of each of these components are not fully understood.

Interestingly, $U$. necator sensitivities to azoxystrobin, pyraclostrobin, and trifloxystrobin did not correlate as strongly or as uniformly as expected, based upon the existence of cross-resistance between fungicides of this group for a number of plant pathogens (18). However, the results were comparable to those found for crosssensitivities published for U. necator to the DMI fungicides fenarimol, myclobutanil, and triadimenol (10). Perhaps our results were due to the narrow range of sensitivities of the isolates tested to the strobilurins and the limited sample size used. Nevertheless, it would have been interesting to have had tested isolates with a wider range of sensitivities, including those with high levels of strobilurin insensitivity, to make these comparisons and document crossresistance between strobilurins for $U$. necator. However, the present study appears to be the first published record to document the sensitivity distribution of this pathogen to strobilurin fungicides.

As seen with previous studies using grape leaf disks and strobilurin fungicides (37), there was considerable phytotoxicity caused by kresoxim-methyl at concentrations higher than $4.0 \mu \mathrm{g} / \mathrm{ml}$, a concentration that did not inhibit fully the radial expansion of the isolates of $U$. necator that were tested. Alternate methodologies were not pursued for the purposes of this study, but further studies indicated that treating the leaf disks $24 \mathrm{~h}$ after excision with a spray suspension of formulated kresoxim-methyl (Sovran 50WP) allowed for the application of fungicide as high as $64 \mu \mathrm{g} / \mathrm{ml}$ without phytotoxicity. Although not applicable for this study, this method would allow for the application of this type of leaf disk assay for future sensitivity monitoring for U. necator to kresoxim-methyl.

The development of practical resistance to strobilurin fungicides by several plant- pathogenic fungi and oomycetes appears to be caused by the rapid buildup of highly resistant phenotypes, resulting in qualitative, disruptive shifts in their sensitivity distributions with respect to these materials $(11,12,17)$. However, the risk of quantitative, directional shifts that have conferred practical resistance to DMI fungicides for many plant pathogens, including $U$. necator $(10,40)$, is unclear for the strobilurins. Within this context, it is important to note the pronounced difference in the range of sensitivities that were detected in the baseline population with respect to azoxystrobin versus myclobutanil (i.e., 7.5versus 140-fold, respectively). Typically, practical resistance to DMI fungicides has developed when fungicide rates that controlled the vast majority of the pathogen population fail to provide adequate control of the least sensitive phenotypes at the edge of such broad ranges, allowing them to build up to damaging levels $(10,20,23)$.

In contrast, our results suggest that the risk and impact of quantitative shifts in sensitivity to azoxystrobin, although measurable, may be relatively minor with respect to the narrow range of sensitivities that were detected among isolates of $U$. necator. Even for the least-sensitive $U$. necator isolates that we found, azoxystrobin provided complete disease control in a 1-day protectant assay when used at a rate as low as $10 \%$ of that recommended for field use, although longer intervals between fungicide treatment and inoculation were not tested to determine the duration of this activity. Nevertheless, such reduced-rate applications made 5 days after inoculation clearly provided a selective pressure favoring the least-sensitive individuals within the pathogen population and an attendant reduction in disease control. Thus, maintenance of full recommended fungicide rates, uniform spray coverage to protect all susceptible host tissues, and the avoidance of extended application intervals (particularly if used in a postinfection mode, either intentionally or by default, e.g., on leaf tissues that have emerged since the last fungicide application) should minimize this risk. However, these techniques are unlikely to affect the selection for a qualitative, disruptive shift toward resistance, since it is primarily dependent on the number of selective events (fungicide applications) to which the pathogen is exposed (30).

It is within the context of potential quantitative shifts in sensitivities to strobilurins among populations of $U$. necator that the relationship between sensitivities to azoxystrobin and myclobutanil must be considered. Our results show a lack of independence between sensitivities to these two unrelated fungicides. In this study, we have referred to this as "cross-sensitivity" versus "cross-resistance," since this relationship is not equivalent to the case when a genetic change in an individual confers resistance to a whole class of related chemistries (18). This relationship between azoxystrobin and myclobutanil sensitivities is similar to that which has been documented for the relationship between sensitivities to dodine and DMI fungicides for $V$. inaequalis (21). The mechanism underlying this relationship is unknown. An active efflux mechanism has been suggested as a potential contributor to the expression of pleiotropic resistance to fungicides $(6,7,19)$, but such activity in plant-pathogenic fungi is still poorly understood. Alternatively, it is possible that the development of fungicide resistance in individual isolates of a plantpathogenic fungus may predispose those individuals to more rapid development of resistance to additional classes of unrelated fungicides (double resistance) (22). Nevertheless, relative to the baseline site with no exposure to either DMI or strobilurin fungicides, sensitivities to azoxystrobin had shifted at the DMI-resistant site, where prolonged usage of DMI fungicides has led

Table 4. Analysis of variance for disease severity for Vitis vinifera cv. Riesling seedlings treated with protectant or postinfection applications of azoxystrobin at 0 to $250 \mu \mathrm{g}$ a.i./ml and inoculated with isolates of Uncinula necator of either high or low azoxystrobin sensitivity

\begin{tabular}{|c|c|c|c|c|c|}
\hline \multirow[b]{3}{*}{ Source of variation } & \multirow[b]{3}{*}{ df } & \multicolumn{4}{|c|}{ Disease severity $^{\mathrm{w}, \mathrm{x}}$} \\
\hline & & \multicolumn{2}{|c|}{ Protectant $^{y}$} & \multicolumn{2}{|c|}{ Postinfection $^{\mathrm{z}}$} \\
\hline & & MS & $\boldsymbol{F}$ & MS & $\boldsymbol{F}$ \\
\hline Sensitivity & 1 & 0.0341 & $7.79 *$ & 0.8603 & $205.81 * * *$ \\
\hline Concentration & 4 & 0.9116 & $208.12 * * *$ & 0.4067 & $97.30 * * *$ \\
\hline Linear & 1 & 3.4313 & $783.39 * * *$ & 1.5535 & $371.65 * * *$ \\
\hline Quadratic & 1 & 0.1195 & $27.28 * * *$ & 0.0005 & 0.13 \\
\hline Cubic & 1 & 0.0944 & $21.55 * * *$ & 0.0088 & 2.10 \\
\hline Quartic & 1 & 0.0011 & 0.26 & 0.0640 & $15.32 * * *$ \\
\hline Sensitivity $\times$ concentration & 4 & 0.0114 & 2.60 & 0.0664 & $15.88 * * *$ \\
\hline Linear & 1 & 0.0040 & 0.92 & 0.0352 & $8.43 * *$ \\
\hline Quadratic & 1 & 0.0218 & $4.97 *$ & 0.1899 & $45.42 * * *$ \\
\hline Cubic & 1 & 0.0095 & 2.17 & 0.0403 & $9.65 * *$ \\
\hline Quartic & 1 & 0.0103 & 2.34 & 0.0000 & 0.00 \\
\hline Error & 20 & 0.0044 & & 0.0042 & \\
\hline
\end{tabular}

\footnotetext{
${ }^{\mathrm{w}} F$ values are significant at $P \leq 0.05(*), P \leq 0.01(* *)$, and $P \leq 0.001(* * *)$ as noted.

${ }^{\mathrm{x}}$ Disease severity was analyzed following arcsine square root transformation of the data.

y Protectant applications were made 1 day before inoculation.

${ }^{\mathrm{z}}$ Postinfection applications were made 5 days after inoculation.
} 
to the development of practical resistance to myclobutanil.

Although a shift in azoxystrobin sensitivity was apparent in the population treated exclusively with myclobutanil, the extent of this shift was not severe enough to compromise control by azoxystrobin, as evidenced by the seedling assays, when $10 \%$ to full rates of the fungicide were used in a protectant manner or when full rates were applied postinfection. Furthermore, rotational programs incorporating both azoxystrobin and myclobutanil provided good control of powdery mildew in both years where it had been tested, in addition to halting further shifts toward myclobutanil insensitivity in 1999, compared with isolates recovered from the unsprayed and myclobutanil-only treated vines. The historical performance of myclobutanil at the DMI-resistant site clearly indicated that the performance of this fungicide was compromised, and the control provided by myclobutanil-only spray programs would not be acceptable commercially. The spray programs in 1998 and 1999 that included azoxystrobin provided superior disease control, indicating that azoxystrobin contributed to the control of DMI-resistant individuals that would otherwise not have been as well controlled in a myclobutanil-only spray program. Thus, based on our results, we suggest that such programs rotating strobilurin and DMI fungicides are viable options for limiting the use of both materials while providing commercially acceptable disease control.

For practical resistance to the strobilurins by $U$. necator, the risk and timing of resistance development is still unclear. The results presented by this study provide important information to assist in monitoring shifts in sensitivity over the long term. Additionally, we provide information on an unexpected relationship in $U$. necator between azoxystrobin and myclobutanil sensitivities, that can serve as a model for other DMI-strobilurin interactions as well as provide information for additional studies on cross sensitivities between otherwise unrelated fungicides.

\section{ACKNOWLEDGMENTS}

We thank H. N. Burr and J. Albani for assistance in performing laboratory assays, J. A. Burr and D. G. Riegel for technical assistance, A. Ficke, D. M. Gadoury, G. Olaya (Syngenta Crop Protection), and H. L Ypema (BASF Agricultural Products Center) for technical advice, M. Gumpertz (North Carolina State University) for help with log-normal statistical analysis, and W. Köller for insight and helpful suggestions.

\section{LITERATURE CITED}

1. Ammerman, E., Lorenz, G., Schelberger, K., Mueller, B., Kirstgen, R., and Sauter, H. 2001. BAS $500 \mathrm{~F}-$ the new broad-spectrum strobilurin fungicide. Pages 541-548 in: Brighton Crop Protection Conference-Pests and Diseases-2000. Vol. 2. Major Print, Nottingham, UK.

2. Ammerman, E., Lorenz, G., Schelberger, K., Wenderoth, B., Sauter, H., and Rentzea, C.
1992. BAS $490 \mathrm{~F}-\mathrm{A}$ broad spectrum fungicide with a new mode of action. Pages 403410 in: Brighton Crop Protection Conference-Pests and Diseases-1992. Vol. 1. Lavenham Press, Lavenham, Suffolk, UK.

3. Baldwin, B. C., Clough, J. M., Godfrey, C. R. A., Godwin, J. R., and Wiggins, T. E. 1996. The discovery and mode of action of ICIA5504. Pages 69-78 in: Modern Fungicides and Antifungal Compounds. H. Lyr, P. E. Russell, and H. D. Sisler, eds. Intercept, Andover, Hants, UK.

4. Casella, G., and Berger, R. L. 1990. Statistical Inference. Wadsworth \& Brooks, Pacific Grove, CA.

5. Colson, A. M. 1993. Random mutant generation and its utility in uncovering structural and functional features of cytochrome $\mathrm{b}$ in Saccharomyces cerevisiae. J. Bioenerg. Biomembr. 25:211-220.

6. Del Sorbo, G., Schoonbeek, H., and DeWaard, M. A. 2000. Fungal transporters involved in efflux of natural toxic compounds and fungicides. Fungal Genet. Biol. 30:1-15.

7. DeWaard, M. A. 1997. Significance of ABC transporters in fungicide sensitivity and resistance. Pestic. Sci. 51:217-275.

8. DiRago, J. P., and Colson, A. M. 1988. Molecular basis of resistance to myxothiazol, mucidin (Strobilurin A), and stigmatellin. J. Biol. Chem. 263:12564-12570.

9. Doster, M. A., and Schnathorst, W. C. 1985. Effects of leaf maturity and cultivar resistance on development of the powdery mildew fungus on grapevines. Phytopathology 75:318321.

10. Erickson, E. O., and Wilcox, W. F. 1997. Distributions of sensitivities to three sterol demethylation inhibitor fungicides among populations of Uncinula necator sensitive and resistant to triadimefon. Phytopathology 87:784-791.

11. Fungicide Resistance Action Committee. 1998. 1998 Status report and recommended fungicide resistance management guidelines. Global Crop Protection Federation. On-line publication.

12. Fungicide Resistance Action Committee. 1999. 1999 Status report and recommended fungicide resistance management guidelines. Global Crop Protection Federation. On-line publication.

13. Gilbert, R. O. 1987. Statistical Methods for Environmental Pollution Monitoring. John Wiley \& Sons, New York.

14. Gisi, U., Hermann, D., Ohl, L., and Steden, C. 1997. Sensitivity profiles of Mycosphaerella graminicola and Phytophthora infestans populations to different classes of fungicides. Pestic. Sci. 51:290-298.

15. Gold, R. E., Ammerman, E., Koehl, H., Leinhos, G. M. E., Lorenz, G., Speakman, J. B., Stark-Urnau, M., and Sauter, H. 1996. The synthetic strobilurin BAS $490 \mathrm{~F}$ : Profile of a modern fungicide. Pages 79-92 in: Modern Fungicides and Antifungal Compounds. $\mathrm{H}$. Lyr, P. E. Russell, and H. D. Sisler, eds. Intercept, Andover, Hants, UK.

16. Gubler, W. D., Ypema, H. L., Ouimette, D. G., and Bettiga, L. J. 1996. Occurrence of resistance in Uncinula necator to triadimefon, myclobutanil, and fenarimol in California grapevines. Plant Dis. 80:902-909.

17. Heaney, S. P., Hall, A. A., Davies, S. A., and Olaya, G. 2001. Resistance to fungicides in the $\mathrm{Q}_{0} \mathrm{I}-\mathrm{STAR}$ cross resistance group: Current perspectives. Pages 755-762 in: Brighton Crop Protection Conference-Pests and Diseases-2000. Vol. 2. Major Print, Nottingham, UK.

18. Heaney, S. P., and Knight, S. C. 1994. ICIA5504: A novel broad-spectrum systemic fungicide for use on fruit, nut and horticul- tural crops. Pages 509-516 in: Brighton Crop Protection Conference-Pests and Diseases1994. Vol. 2. Major Print, Nottingham, UK.

19. Joseph-Horne, T., and Hollomon, D. W. 1997. Molecular mechanisms of azole resistance in fungi. FEMS Microbiol. Lett. 149:141-149.

20. Köller, W., and Wilcox, W. F. 1999. Evaluation of tactics for managing resistance of Venturia inaequalis to sterol demethylation inhibitors. Plant Dis. 83:857-863.

21. Köller, W., and Wilcox, W. F. 2000. Interactive effects of dodine and the DMI fungicide fenarimol in the control of apple scab. Plant Dis. 84:863-870.

22. Köller, W., and Wilcox, W. F. 2001. Evidence for the predisposition of fungicide-resistant isolates of Venturia inaequalis to a preferential selection for resistance to other fungicides. Phytopathology 91:776-781.

23. Köller, W., Wilcox, W. F., Barnard, J., Jones, A. L., and Braun, P. G. 1997. Detection and quantification of resistance of Venturia inaequalis populations to sterol demethylation inhibitors. Phytopathology 87:184-190.

24. Köller, W., Wilcox, W. F., and Jones, A. L. 1999. Quantification, persistence, and status of dodine resistance in New York and Michigan orchard populations of Venturia in aequalis. Plant Dis. 83:66-70.

25. Kraiczy, P., Haase, U., Gencic, S., Findt, S. Anke, T., Brandt, U., and Von Jagow, G. 1996. The molecular basis for the natural resistance of the cytochrome $b c_{1}$ complex from strobilurin-producing basidiomycetes to center $\mathrm{Q}_{\mathrm{p}}$ inhibitors. Eur. J. Biochem. 235:54-63.

26. Leung, H., Nelson, R. J., and Leach, J. E. 1993. Population structure of plant pathogenic fungi and bacteria. Adv. Plant Pathol. 10:157-205.

27. Margot, P., Huggenberger, J., and Amrein, J 1998. CGA 279202: A new broad-spectrum strobilurin fungicide. Pages 375-382 in: Brighton Crop Protection Conference-Pests and Diseases-1998. Major Print, Nottingham, UK.

28. Mitsuhiro, I., Michio, M., Hideyuki, T., Hasagawa, R., Ichiba, T., Yoshio, H., and Takeda, R. 1999. Structural and fungicidal activities of methoxy-iminophenylacetamide derivatives. Pestic. Sci. 55:347-349.

29. Olaya, G., and Köller, W. 1999. Baseline sensitivities of Venturia inaequalis populations to the strobilurin fungicide kresoximmethyl. Plant Dis. 83:274-278.

30. Olaya, G., and Köller, W. 1999. Diversity of kresoxim-methyl sensitivities in baseline populations of Venturia inaequalis. Pestic. Sci. 55:1083-1088

31. Pearson, R. C. 1988. Powdery mildew. Pages 9-11 in: Compendium of Grape Diseases. R. C. Pearson and A. C. Goheen, eds. American Phytopathological Society, St. Paul, MN.

32. Smith, F. D., Parker, D. M., and Köller, W. 1991. Sensitivity distribution of Venturia inaequalis to the sterol demethylation inhibitor flusilazole: Baseline sensitivity and implications for resistance monitoring. Phytopathology 81:392-396.

33. Wilcox, W. F., and Riegel, D. G. 1997. Evaluation of fungicide programs for contro of grapevine powdery mildew, 1996. Fungic. Nematicide Tests 52:82-83.

34. Wilcox, W. F., and Riegel, D. G. 1998 Evaluation of fungicide programs for control of grapevine powdery mildew, 1997. Fungic. Nematicide Tests 53:107-108.

35. Wilcox, W. F., Riegel, D. M., Erickson, E. O., and Burr, J. A. 1998. Vineyard evaluation of resistance-management strategies for DMI fungicides and Uncinula necator. Phytopathology 88:S97.

36. Wilcox, W. F., Riegel, D. G., and Wong, F. P. 1999. Evaluation of fungicide programs for 
control of grapevine powdery mildew, 1998. Fungic. Nematicide Tests 54:106-107.

37. Wong, F. P., and Wilcox, W. F. 2000. Distribution of baseline sensitivities to azoxystrobin among isolates of Plasmopara viticola. Plant Dis. 84:275-281

38. Wong, F. P., and Wilcox, W. F. 2001. Comparative physical modes of action of azoxystrobin, mancozeb, and metalaxyl against Plasmopara viticola (grapevine downy mildew). Plant Dis. 85:649-656.

39. Ypema, H. L., and Gold, R. E. 1999. Kresoxim-methyl: Modification of a naturally occurring compound to produce a new fungicide. Plant Dis. 83:4-17.

40. Ypema, H. L., Ypema, M., and Gubler, W. D. 1997. Sensitivity of Uncinula necator to benomyl, triadimefon, myclobutanil, and fenarimol in California. Plant Dis. 81:293297.
41. Zheng, D., Olaya, G., and Köller, W. 2000. Characterization of Venturia inaequalis mutants resistant to the strobilurin-related fungicide kresoxim-methyl. Curr. Genet. 38:148 155.

42. Ziogas, B. N., Baldwin, B. C., and Young, J. E. 1997. Alternative respiration: A biochemical mechanism of resistance to azoxystrobin (ICIA 5504) in Septoria tritici. Pestic. Sci. 50:28-34. 